\title{
Preparation and Investigation of a Novel Organic Polymer Consisting of 2,2,6,6-Tetramethylpiperidine-N-oxy as a Cathode Active Material in Li-Ion Batteries
}

\author{
Emre Biçer ${ }^{1}$ and Atilla Öktemer ${ }^{2}$ \\ ${ }^{1}$ TUBITAK Marmara Research Center, Energy Institute, Gebze 41470, Kocaeli, Turkey \\ ${ }^{2}$ Department of Chemistry, Faculty of Science, Ankara University, Tandogan, 06100 Ankara, Turkey
}

Correspondence should be addressed to Emre Biçer; bicer_emre@yahoo.com

Received 24 March 2013; Accepted 1 July 2013

Academic Editor: Kenneth I. Ozoemena

\begin{abstract}
Copyright ( 2013 E. Biçer and A. Öktemer. This is an open access article distributed under the Creative Commons Attribution License, which permits unrestricted use, distribution, and reproduction in any medium, provided the original work is properly cited.

In the present study, a novel organic polymer consisting of 2,2,6,6-tetramethylpiperidine- $\mathrm{N}$-oxyl group as an electroactive center is employed by synthesizing it from a commercially ready polymer. An investigation on electrochemical and battery properties of this material as a cathode active material in different electrolyte salts was conducted. A coin cell shows a discharge capacity of $40 \mathrm{mAh} \mathrm{g}^{-1}$ at $1 C$ which is $76 \%$ of its theoretical capacity. It is observed that there is no significant decrease in capacity value even at $2 C$ and $5 C$ which indicates that it is applicable for the high-power applications. Besides, a good cycle stability is obtained with the organic radical battery.
\end{abstract}

\section{Introduction}

The use of conjugated polymers as electroactive material alternative to the inorganic insertion compounds has been extensively reported in the literature. However, no satisfactory results were obtained [1]. Organic radical batteries bearing nitroxide group as an electroactive center appeared as a new concept in Li-ion batteries. Electrochemical oxidation and reduction properties of the nitroxide group enable it to act as an active center of the organic radical battery. In addition, the stability of TEMPO (2,2,6,6-tetramethylpiperidine$\mathrm{N}$-oxy) containing nitroxide group at ambient conditions makes the compound a perfect electroactive material. The nitroxide radical oxidized to oxyammonium cation by losing an electron, whereas it is reduced to aminoxy anion by gaining an electron (Figure 1). Electrochemical reactions occur by the single electron transfer caused by the radical active center of TEMPO molecule. TEMPO and PROXYL (2,2,5,5-tetramethyl-1-pyrrolidinyloxy) groups bearing nitroxide group substituted to polymer backbone as a repeating unit are synthesized as cathode active materials.
The first organic radical battery with poly $(2,2,6,6$ tetramethylpiperidinyloxy methacrylate) (PTMA) polymerization of 2,2,6,6-tetramethylpiperidine- $\mathrm{N}$-oxyl methacrylate containing a nitroxide group as an active center was reported by Nakahara and coworkers [2, 3]. In following years, different polymers substituted with TEMPO and PROXYL moieties were employed as cathode active materials in Li-ion batteries such as polyethers [4-6], polyacetylene [7], polynorbornene [8, 9], poly(7-oxanorbornene) [10], cellulose [11], DNA complexes [12], polythiophenes [13], and polyalkenes [14] illustrated in Figure 2.

While the electrochemical reaction occurs with nitroxide radical, during charging and discharging every different polymer substituted with TEMPO has to be of the same capacity. Nevertheless, different capacities were observed with different polymers. The difference in the mechanical aspects of the polymers constitutes the reason thereof.

The charge- and discharge-mechanism of the organic radical battery is illustrated in Figure 3. During the charging of organic radical battery the nitroxide radical oxidizes to oxoammonium cation, while forming an oxoammonium 


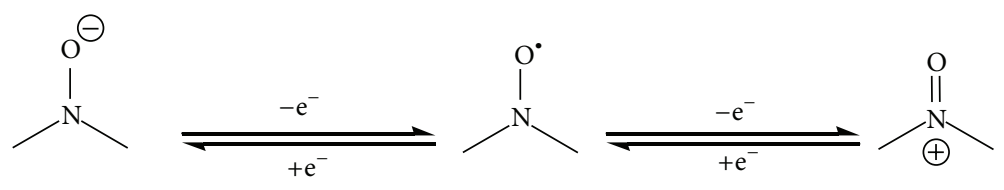

FIGURE 1: Redox couple of the nitroxide radical.<smiles>CCC(C)(C)C(=O)OC1CC(C)(C)N([O])C(C)(C)C1</smiles>

A<smiles>CCC(COC1CC(C)(C)N([O])C(C)(C)C1)OC</smiles>

B<smiles>CC=C(C)C(=O)OC1CC(C)(C)N([O])C(C)(C)C1</smiles>

C<smiles>[X]C1C(C=C)C(C(=O)CC2CC(C)(C)N([O])C(C)(C)C2)C(C(=O)CC2CC(C)(C)N([O])C(C)(C)C2)C1C=C</smiles>

D, X: $\mathrm{CH}_{2}$

FIGURE 2: Various TEMPO substituted cathode active polymers (A) PTMA, (B) polyethers, (C) polyacetylenes, (D) polynorbornene, and (E) poly(7-oxanorbornene).

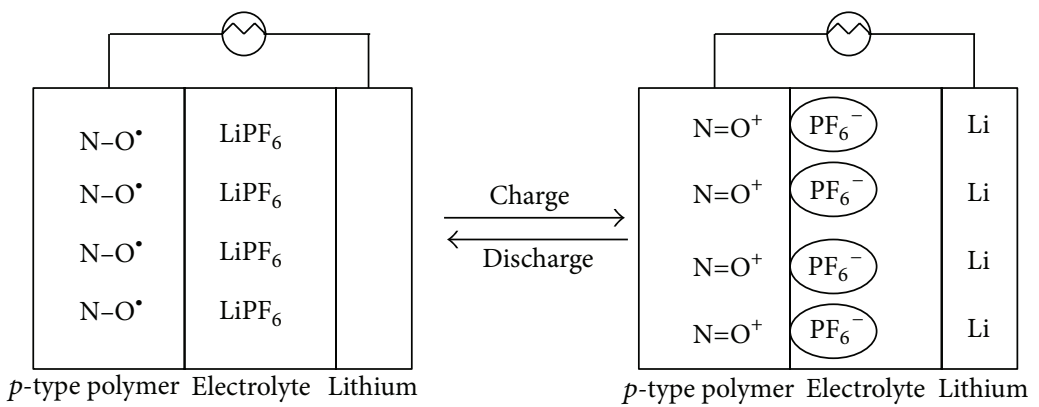

FIGURE 3: The charge/discharge mechanism of the organic radical Li-ion battery.

phosphorus hexafluoride compound with the $\mathrm{PF}_{6}$ counter ion contained in the electrolyte. During the discharge the reaction reverses, converting the oxoammonium cation into nitroxide radical. Meanwhile the phosphorus hexafluoride is returned to the electrolyte and forms $\mathrm{LiPF}_{6}$ salt.

The aim of this study was to synthesize a new class of compound from a commercially available starting material for employing it as cathode active material in organic radical battery. We report the investigation of electrochemical studies by cyclic voltammetry and impedance measurements and the charge/discharge characteristics of a $\mathrm{Li} /$ cathode active material coin cell. Also, the commercial availability of starting material combined with the fact of it being synthesized in high volumes makes it economically feasible compared to other cathode active materials. Besides, the ease of synthesis makes it a candidate active material among the others.

\section{Experimental}

All solvents and PVdF (polyvinylidenfluoride) were purchased from Merck. Commercially available battery grade NMP (N-methyl pyrrolidone) and $\mathrm{LiPF}_{6}$ salt were purchased from Alfa Aeser. Super P carbon was purchased from Timcal Co. Also, commercially available polymer compound Uvinul $5045 \mathrm{H}\left(\mathrm{C}_{32} \mathrm{~N}_{58} \mathrm{~N}_{2} \mathrm{O}_{2}\right)_{n}$ was purchased from BASF Turkey. Electrochemical measurements were conducted with PAR VersaSTAT multichannel potentiostat/galvanostat. Thermogravimetric analysis was performed on Mettler-Toledo TGA851 with a heating rate of $5^{\circ} \mathrm{C} / \mathrm{min}$. Elemental Analysis was performed by Leco-932-CHNS-O instrument. Kurabo mixer was used for mixing/deaerating purposes. Fabrication of button cells was assembled in Vigor 1500GS glove box under Argon atmosphere. All electrochemical tests were conducted 

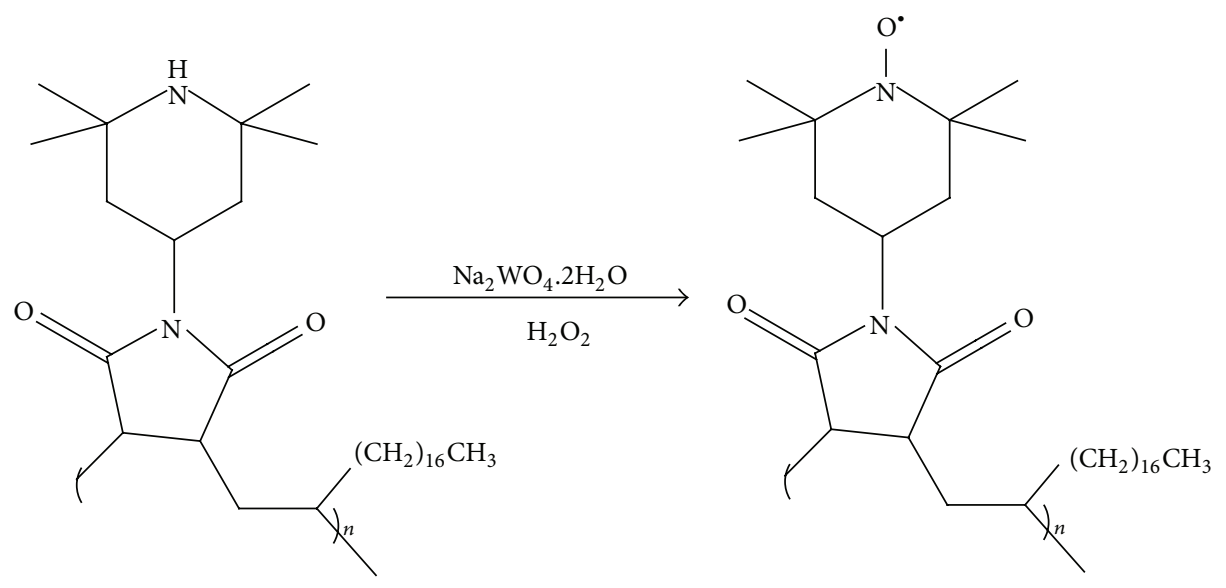

FIGURE 4: Synthesis of the organic radical polymer.

with CR2032 button cells purchased from MTI corp. All chemicals were used without further purification.

2.1. Synthesis of the Compounds. The cathode active material was synthesized by the oxidation of the commercially available polymer compound $\left(\mathrm{C}_{32} \mathrm{~N}_{58} \mathrm{~N}_{2} \mathrm{O}_{2}\right)_{n}$. The starting polymer was dissolved in chloroform and methanol solution $(1: 1)$. To this solution, $0.01 \mathrm{~g}$ sodium tungstate was added as an oxidation catalyst and then $30 \%$ hydrogen peroxide was added dropwise carefully. The solution was stirred overnight at room temperature. The orange precipitate was filtered off and washed with chloroform three times to remove catalyst and other soluble side-products and then the residue was dried under reduced pressure at $50^{\circ} \mathrm{C}$ to afford the pure orange polymer whose color was due to the TEMPO radical. The obtained polymer was insoluble in common organic solvents. FTIR (KBr disc, $\left.\mathrm{cm}^{-1}\right): 2950\left(v_{\mathrm{C}-\mathrm{H}}\right), 2900\left(v_{\mathrm{C}-\mathrm{H}}\right)$, $1700\left(v_{\mathrm{C}=\mathrm{O}}\right), 1620,1480\left(v_{\mathrm{N}-\mathrm{O}}\right)$. GPC: $M_{n}=2953 \mathrm{~g} / \mathrm{mol}$; $M_{w} / M_{n}=1.4$. Analysis of $\mathrm{C}_{32} \mathrm{H}_{57} \mathrm{~N}_{2} \mathrm{O}_{3}(517 \mathrm{~g} / \mathrm{mol})$ : calcd. $\mathrm{C}=74.23, \mathrm{H}=11.10, \mathrm{~N}=5.41$; found $\mathrm{C}=74.82 \mathrm{H}=11.53 \mathrm{~N}=$ 5.62 .

2.2. Preparation of the Composite Electrodes and Electrochemical Measurements. The composite electrodes were prepared as follows. A radical polymer (20\%), Timcal Super P carbon (70\%), and PVdF (10\%) were mixed and added NMP to make a slurry. The suspension was dispersed in a mixer/deaerator. The dispersed slurry was pasted on a $15 \mathrm{~mm}$ diameter aluminum foil by using a spin-coater and then dried in an oven at $50^{\circ} \mathrm{C}$. The composite electrode was hot-pressed and dried under vacuum at $50^{\circ} \mathrm{C}$ for $15 \mathrm{~h}$. Then it was taken into the glove box in order to prepare a coin battery (CR2032). Cyclic voltammetry was performed fabricated for composite electrode/Super $\mathrm{P}$ in a voltage range of $3.0-4.2 \mathrm{~V}$ at scan rates of $1,2,5$, and $10 \mathrm{mV} \mathrm{s}^{-1} \cdot 0.1 \mathrm{M} \mathrm{LiAsF} 6, \mathrm{LiBF}_{4}$, and $\mathrm{LiPF}_{6}$ solution of ethylene carbonate/diethyl carbonate $(1: 1$, $\mathrm{v} / \mathrm{v}$ ) was used as electrolyte. Lithium metal was used as the reference and counter electrode and the composite electrode was used as the working electrode.

2.3. Fabrication of the Batteries and Battery Performance. The coin type (CR2032) cell was fabricated by stacking electrodes with Whatman glass fiber separator film in glove box. The cathode was set to a coin-type cell together with a lithium metal anode and a separator. A composite solution of ethylene carbonate and diethyl carbonate $(1: 1, \mathrm{v} / \mathrm{v})$ containing $1 \mathrm{M}$ of $\mathrm{LiPF}_{6}$ was used as an electrolyte $\left(1 \mathrm{M}\right.$ solutions of $\mathrm{LiAsF}_{6}$ and $\mathrm{LiBF}_{4}$ are also used). The performance of the battery was tested by repeating galvanostatic charge/discharge at the scan rates of $1 C\left(50 \mathrm{~mA} \mathrm{~g}^{-1}\right), 2 C\left(100 \mathrm{~mA} \mathrm{~g}^{-1}\right)$, and $5 C$ $\left(250 \mathrm{~mA} \mathrm{~g}^{-1}\right)$. Also, theoretical capacity of the cathode active material was calculated from the literature [15].

\section{Results and Discussion}

The commercially available polymer $\left(\mathrm{C}_{32} \mathrm{H}_{58} \mathrm{~N}_{2} \mathrm{O}_{2}\right)_{n}$ was used as starting material. The secondary amine group on the 2,2,6,6-tetramethylpiperidine substituted to the polymer backbone was converted into nitroxide through a basic reaction using $\mathrm{H}_{2} \mathrm{O}_{2}$ in conjunction with $\mathrm{Na}_{2} \mathrm{WO}_{4} \cdot 2 \mathrm{H}_{2} \mathrm{O}$ catalyst and used as the cathode active material in the $\mathrm{Li}$-ion battery (Figure 4). Since the nitrogen atom of the piperidine is oxidized to nitroxide, the solution is turned from yellow to orange. The reaction is kept overnight at room temperature in order to form nitroxide radical in the polymer backbone. The commercial availability of starting material of the cathode active material combined with the fact of it being synthesized in high volumes makes it economically feasible compared to other chemicals.

Gel permeation chromatography (GPC) of the organic radical polymer indicated that the weight average molar mass of the polymer $\left(M_{w}\right)$ is $4221 \mathrm{~g} \mathrm{~mol}^{-1}$, while the number average molar mass is $\left(M_{n}\right) 2953 \mathrm{~g} \mathrm{~mol}^{-1}$. In this case, the polydispersity of the polymer $\left(M_{w} / M_{n}\right)$ is found to be 1.4 which indicates a homogenous polymer distribution. 
Furthermore, the thermogravimetric analysis (TGA) of the organic radical polymer showed us that it is stable up to thermal decomposition temperature of $250^{\circ} \mathrm{C}$. Besides, it is observed that $10 \%$ of the polymer decomposed around $315^{\circ} \mathrm{C}$ (Figure 5).

For the cyclic voltammogram of the compound, various electrolytes were used at $1 \mathrm{mV} \mathrm{s}^{-1}$ scan rate (Figure 6). Similar peak-to-peak separation values were observed for all electrolytes. While the separation value for $\mathrm{LiAsF}_{6}$ was found to be $148 \mathrm{mV}$, the values of 167 and $128 \mathrm{mV}$ were observed for $\mathrm{LiBF}_{4}$ and $\mathrm{LiPF}_{6}$, respectively, which proves that the oxidation/reduction reaction of the nitroxide is independent of the electrolyte.

Additionally, when the electrolyte salt is $\mathrm{LiPF}_{6}$, the cyclic voltammogram of the composite electrode at different scan rates was shown in Figure 7. The anodic potential of the composite electrode appeared at $3.73 \mathrm{~V}$, whereas the cathodic potential was $3.59 \mathrm{~V}$. Thus, the peak-to-peak separation $(\Delta E)$ was found as $128 \mathrm{mV}$ at a scan rate of $1 \mathrm{mV} \mathrm{s}^{-1}$. The calculated peak-to-peak separation indicates fast electrode reaction kinetic of the electrochemical reaction. Additionally, an increase of the peak-to-peak separations was observed as the increase of the ratio of scan rates in the composite electrode.

$\mathrm{AC}$ impedance measurements were conducted in the range of $0.01 \mathrm{~Hz}$ to $1 \mathrm{kHz}$ with an $\mathrm{AC}$ amplitude of $10 \mathrm{mV}$. The $x$-axis of the Nyquist plot indicates the real part $\left(Z^{\prime}\right)$, whereas the $y$-axis indicates the imaginary part $\left(Z^{\prime \prime}\right)$. The resistances of the electrolyte $\left(R_{s}\right)$ and the composite electrode $\left(R_{f}\right)$ appeared on the $x$-axis of the Nyquist plot of the composite electrode (Figure 8). The impedance of the organic radical polymer was comparatively investigated with electrolyte salts $\mathrm{LiAsF}_{6}, \mathrm{LiBF}_{4}$, and $\mathrm{LiPF}_{6}$. The $R_{s}$ and $R_{f}$ values of the radical battery with $\mathrm{LiPF}_{6}$ used as electrolyte salt were observed to be 8 and 41 ohms, respectively, whereas the same values turned out to be 10 and $35 \mathrm{ohms}$ for $\mathrm{LiAsF}_{6}$ as the electrolyte salt. Finally in case of $\mathrm{LiBF}_{4}$ being used as electrolyte salt, $R_{s}$ and $R_{f}$ values were found to be 16 and 56 ohms, respectively. These results are in good agreement with the organic radical polymers [16]. The lowest electrolyte resistance was achieved in case of $\mathrm{LiAsF}_{6}$, whereas the highest was that of $\mathrm{LiBF}_{4}$. The same ranking was observed for discharge potentials.

The cycle behavior of the cathode active polymer is also investigated versus lithium anode by using different electrolytes $\mathrm{LiAsF}_{6}, \mathrm{LiBF}_{4}$ and $\mathrm{LiPF}_{6}$. The determination of the capacity of the cathode active material was realized by chronocoulometry at a constant current density of $1 C$ (1C is defined as the current density at which the charging and discharging of the cell take 1 hour) in a voltage range of 3.0-4.2 V. The initial discharge capacity of the cathode active material was shown in Figure 9. However in case of a different electrolyte use, the capacity was not found to vary. The results obtained were $40 \mathrm{mAhg}^{-1}$ for $\mathrm{LiPF}_{6}, 45 \mathrm{mAh} \mathrm{g}^{-1}$ for $\mathrm{LiBF}_{4}$, and $46 \mathrm{mAh} \mathrm{g}^{-1}$ for $\mathrm{LiAsF}_{6}$, whereas the theoretical capacity was found to be $52 \mathrm{mAhg}^{-1}$. The plateau voltage of the organic radical battery was observed $3.66 \mathrm{~V}$ which is in good agreement with the formal redox potentials.

Concurrently, in an effort to determine the rate capability of the synthesized cathode active material the organic radical

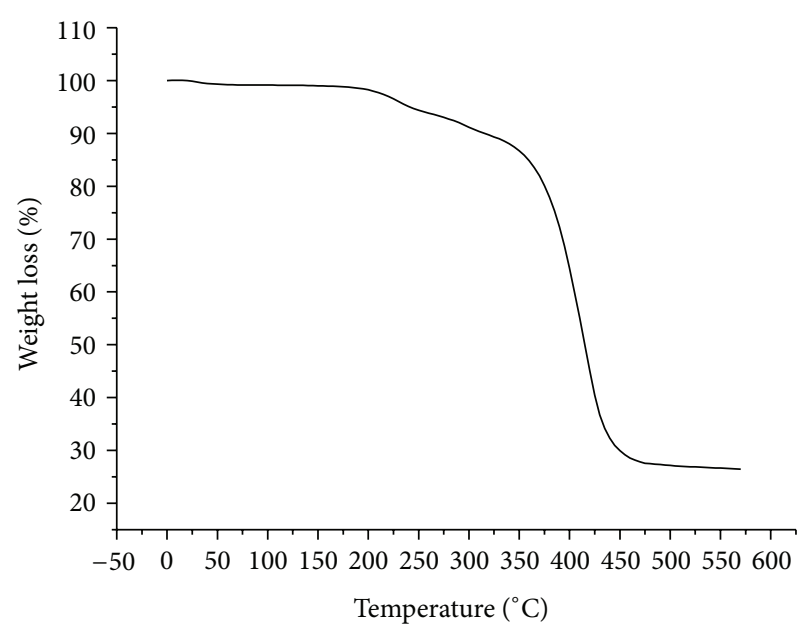

FIgURE 5: Thermogravimetric analysis of the cathode active material.

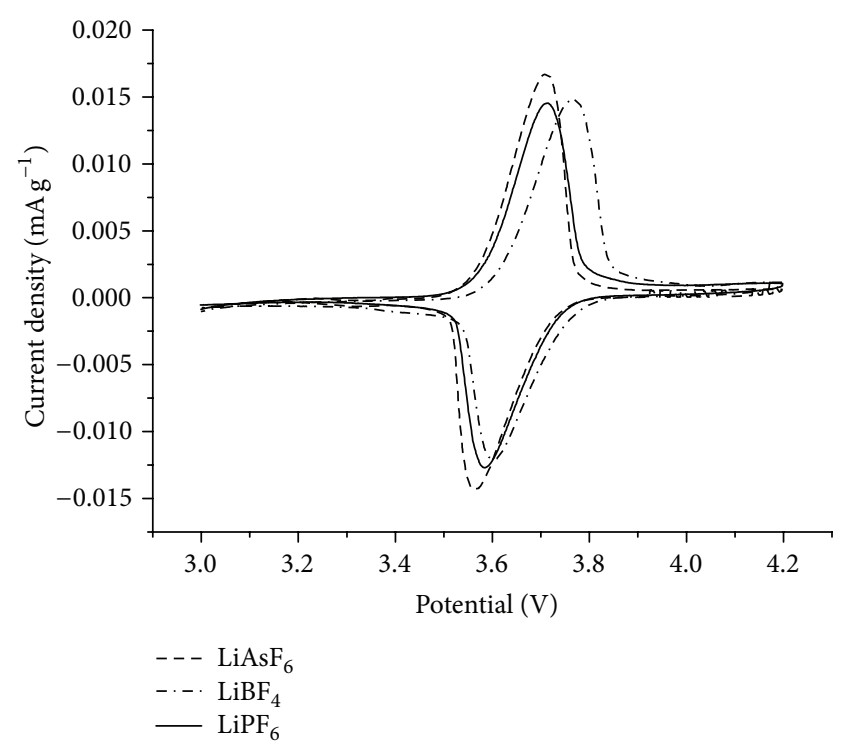

FIgURE 6: The cyclic voltammogram of the organic cathode active polymer with different electrolytes.

battery containing $\mathrm{LiPF}_{6}$ was discharged at $1 \mathrm{C}\left(50 \mathrm{mAg}^{-1}\right)$, $2 \mathrm{C}\left(100 \mathrm{~mA} \mathrm{~g}^{-1}\right)$, and $5 \mathrm{C}\left(250 \mathrm{~mA} \mathrm{~g}^{-1}\right)$ current densities (Figure 10). The discharge capacity of the organic radical battery was found to be $40 \mathrm{mAhg}^{-1}$ at $1 \mathrm{C}$ while it was $35 \mathrm{mAh} \mathrm{g}^{-1}$ at $2 \mathrm{C}$ and also $31 \mathrm{mAh} \mathrm{g}^{-1}$ at $5 \mathrm{C}$. Also, the charge capacities were given in Figure 10. The initial coulombic efficiency at $1 C$ was $76 \%$ whereas $92 \%$ at $2 C$ and $97 \%$ at $5 \mathrm{C}$. Although the observed capacity was not as good as we expected, no significant decrease was observed compared with conventional batteries even at high current densities.

The cycle performance of the organic radical battery is illustrated in Figure 11. During 75 cycles, the organic radical battery stored $97 \%$ of its initial capacity in the presence of electrolyte $\mathrm{LiPF}_{6}$ while $98 \%$ in $\mathrm{LiAsF}_{6}$ and $97 \%$ in $\mathrm{LiBF}_{4}$. But, no significant differences were observed on the cycle 


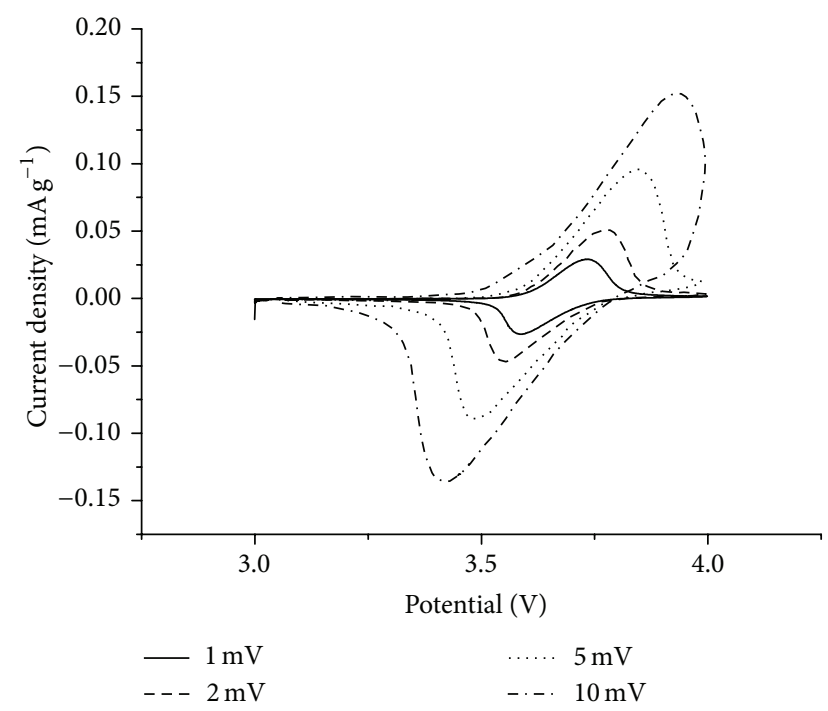

FIGURE 7: Cyclic voltammogram of the composite electrode with various scan rates.

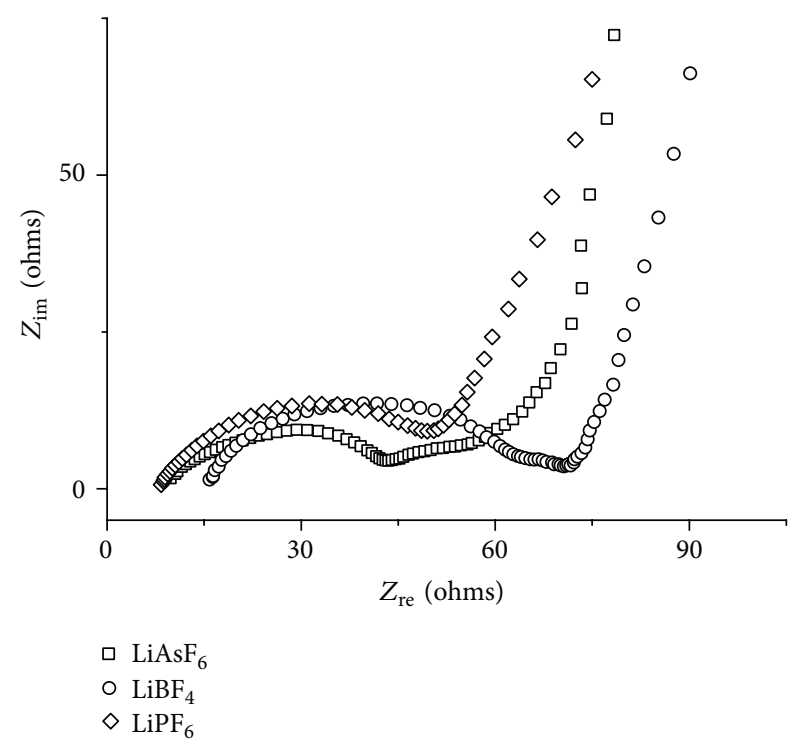

FIGURE 8: Nyquist plot of the composite electrodes with electrolyte salts.

performance of the organic radical battery in case of different electrolyte salts. These results show us the cycle stability and the fast electron transfer character of the nitroxide group independent from different electrolyte salts.

\section{Conclusion}

Consequently, electrochemical reactions occur by the radical active center of TEMPO molecule by a single electron transfer. Even though the organic radical battery showed a good cyclability and high-power capability, it seems poor in terms of capacity. It could reach $88 \%$ of its theoretical capacity $\left(52 \mathrm{mAh} \mathrm{g}^{-1}\right)$. Additionally, various salts were employed as electrolyte to investigate the change in capacity of organic

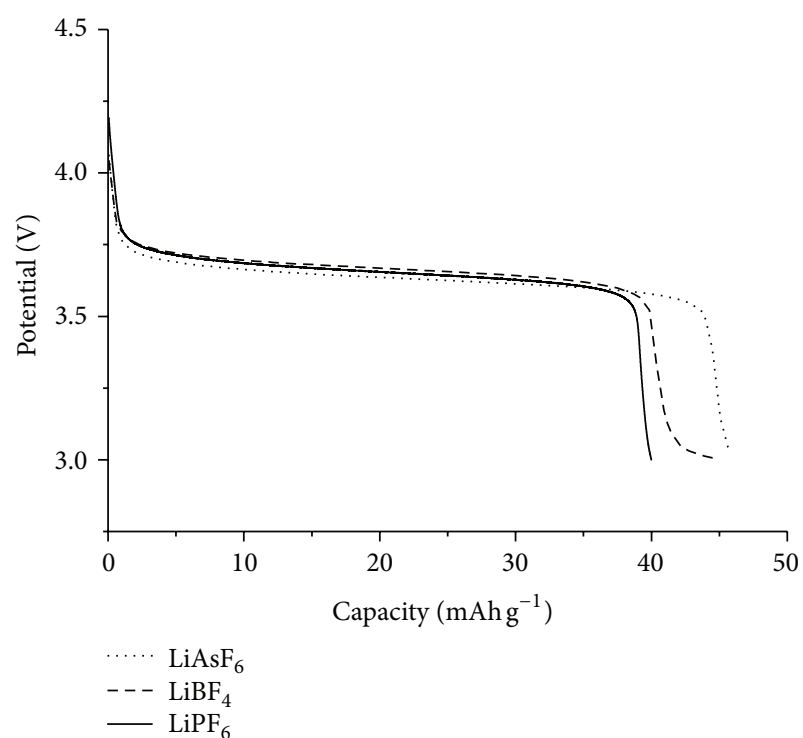

FIGURE 9: The capacity difference with different electrolytes.

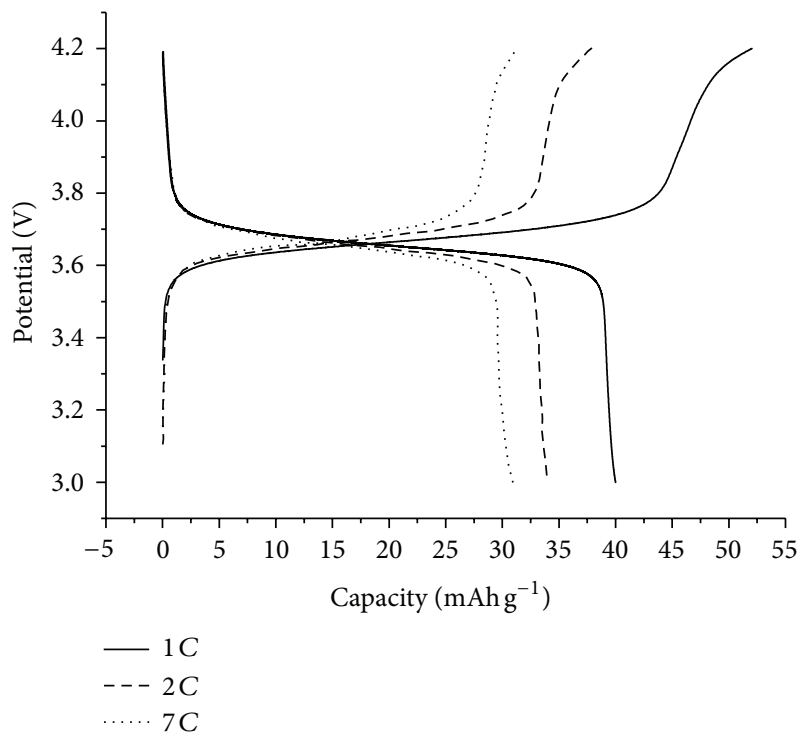

FIGURE 10: Discharge capacity of the organic radical battery at different $C$-rates.

radical batteries. But no significant changes were observed. In this respect, our research group has an effort on increasing the capacity of the cathode active material due to economic superiority of the synthesis.

\section{Conflict of Interests}

The authors declare that there is no conflict of interests with MTI corporation regarding the material discussed in the paper. 


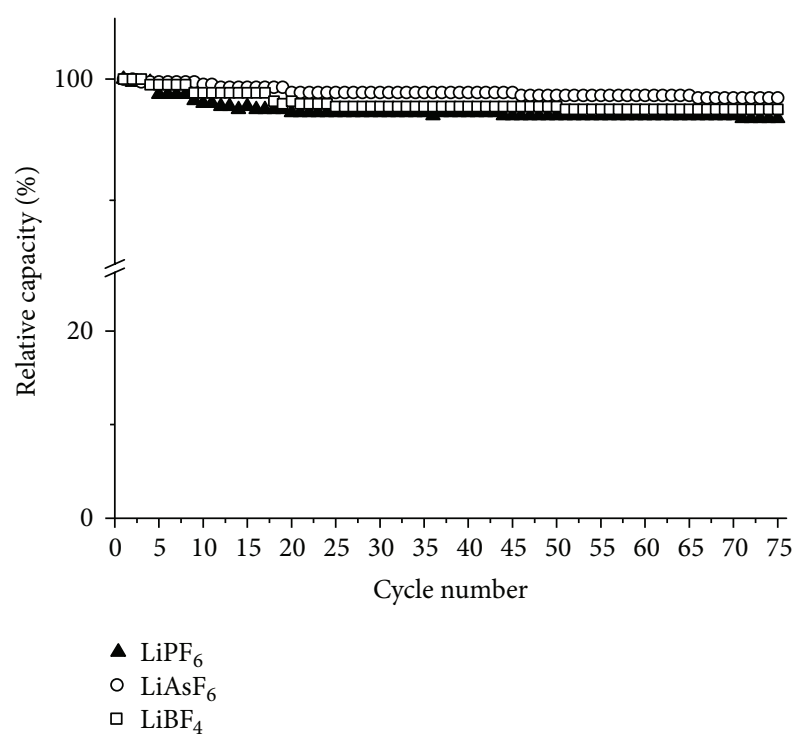

FIGURE 11: The cycle performance of the organic radical battery.

\section{Acknowledgments}

This work was partially supported by Ministry of Development Project "Research and Development Center for Electric Energy Storage Technologies (5092717).” The authors would like to thank BASF-Turkey/Doğanay Kimya for their support of commercially available polymer compound. The authors would like to thank the researchers of the Battery Research Group for their valuable discussions during the studies. They are also grateful to Dr. Günhan Kaytaz for detailed editing of the typescript. Emre Biçer also would like to thank Mrs. Hilal Biçer for her encouragement during the preparation of this paper.

\section{References}

[1] P. Novák, K. Müller, K. S. V. Santhanam, and O. Haas, "Electrochemically active polymers for rechargeable batteries," Chemical Reviews, vol. 97, no. 1, pp. 207-281, 1997.

[2] K. Nakahara, S. Iwasa, M. Satoh et al., "Rechargeable batteries with organic radical cathodes," Chemical Physics Letters, vol. 359, no. 5-6, pp. 351-354, 2002.

[3] H. Nishide, S. Iwasa, Y. Pu, T. Suga, K. Nakahara, and M. Satoh, "Organic radical battery: nitroxide polymers as a cathode-active material," Electrochimica Acta, vol. 50, no. 2-3, pp. 827-831, 2004.

[4] T. Suga, K. Yoshimura, and H. Nishide, "Nitroxide-substituted polyether as a new material for batteries," Macromolecular Symposia, vol. 245-246, pp. 416-422, 2006.

[5] K. Oyaizu, T. Suga, K. Yoshimura, and H. Nishide, "Synthesis and characterization of radical-bearing polyethers as an electrode-active material for organic secondary batteries," Macromolecules, vol. 41, no. 18, pp. 6646-6652, 2008.

[6] K. Oyaizu, T. Kawamoto, T. Suga, and H. Nishide, "Synthesis and charge transport properties of redox-active nitroxide polyethers with large site density," Macromolecules, vol. 43, no. 24, pp. 10382-10389, 2010.
[7] J. Qu, T. Katsumata, M. Satoh et al., "Synthesis and charge/ discharge properties of polyacetylenes carrying 2,2,6,6tetramethyl-1-piperidinoxy radicals," Chemistry, vol. 13, no. 28, pp. 7965-7973, 2007.

[8] T. Katsumata, M. Satoh, J. Wada, M. Shiotsuki, F. Sanda, and T. Masuda, "Polyacetylene and polynorbornene derivatives carrying TEMPO. Synthesis and properties as organic radical battery materials," Macromolecular Rapid Communications, vol. 27, no. 15, pp. 1206-1211, 2006.

[9] T. Katsumata, J. Qu, M. Shiotsuki et al., "Synthesis, characterization, and charge/discharge properties of polynorbornenes carrying 2,2,6,6-tetramethylpiperidine-1-oxy radicals at high density," Macromolecules, vol. 41, no. 4, pp. 1175-1183, 2008.

[10] J. Qu, T. Katsumata, M. Satoh, J. Wada, and T. Masuda, "Poly(7oxanorbornenes) carrying 2,2,6,6-tetramethylpiperidine-1-oxy (TEMPO) radicals: synthesis and charge/discharge properties," Polymer, vol. 50, no. 2, pp. 391-396, 2009.

[11] J. Qu, F. Z. Khan, M. Satoh et al., "Synthesis and charge/discharge properties of cellulose derivatives carrying free radicals," Polymer, vol. 49, no. 6, pp. 1490-1496, 2008.

[12] J. Qu, R. Morita, M. Satoh et al., "Synthesis and properties of DNA complexes containing 2,2,6,6-tetramethyl-1- piperidinoxy (TEMPO) moieties as organic radical battery materials," Chemistry, vol. 14, no. 11, pp. 3250-3259, 2008.

[13] M. Aydin, B. Esat, Ç. Kili, M. E. Köse, A. Ata, and F. Yilmaz, "A polythiophene derivative bearing TEMPO as a cathode material for rechargeable batteries," European Polymer Journal, vol. 47, no. 12, pp. 2283-2294, 2011.

[14] X. Zhang, H. Li, L. Li et al., "Polyallene with pendant nitroxyl radicals," Polymer, vol. 49, no. 16, pp. 3393-3398, 2008.

[15] J. Qu, T. Katsumata, M. Satoh, J. Wada, and T. Masuda, "Synthesis and properties of polyacetylene and polynorbornene derivatives carrying 2,2,5,5-tetramethyl-1-pyrrolidinyloxy moieties," Macromolecules, vol. 40, no. 9, pp. 3136-3144, 2007.

[16] J. Kim, G. Cheruvally, J. Choi et al., "Effect of radical polymer cathode thickness on the electrochemical performance of organic radical battery," Solid State Ionics, vol. 178, no. 27-28, pp. 1546-1551, 2007. 

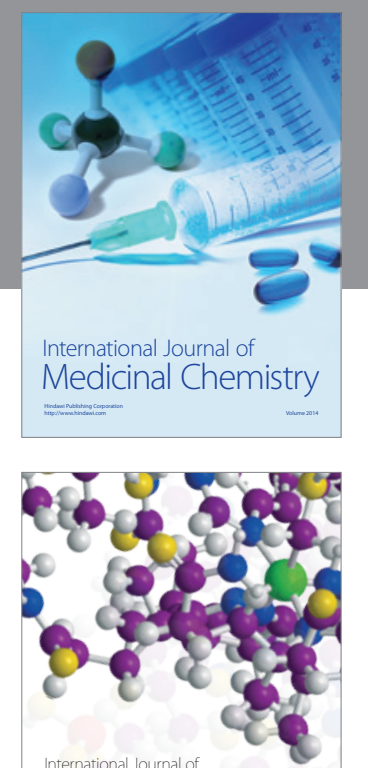

\section{Carbohydrate} Chemistry

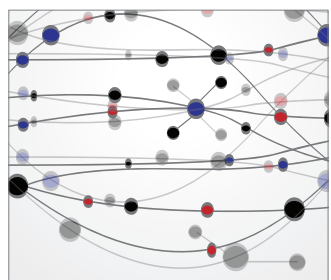

The Scientific World Journal
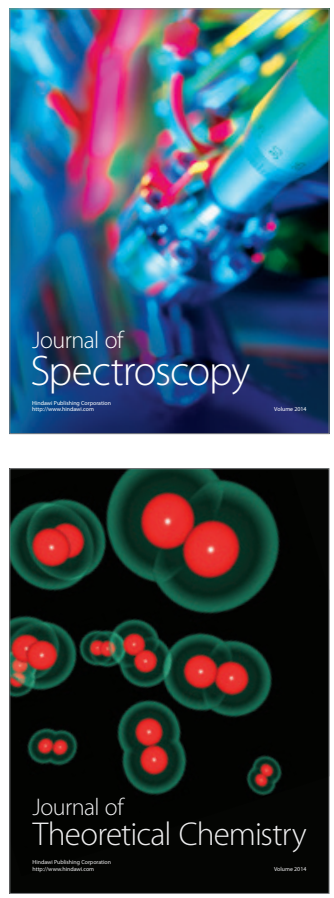
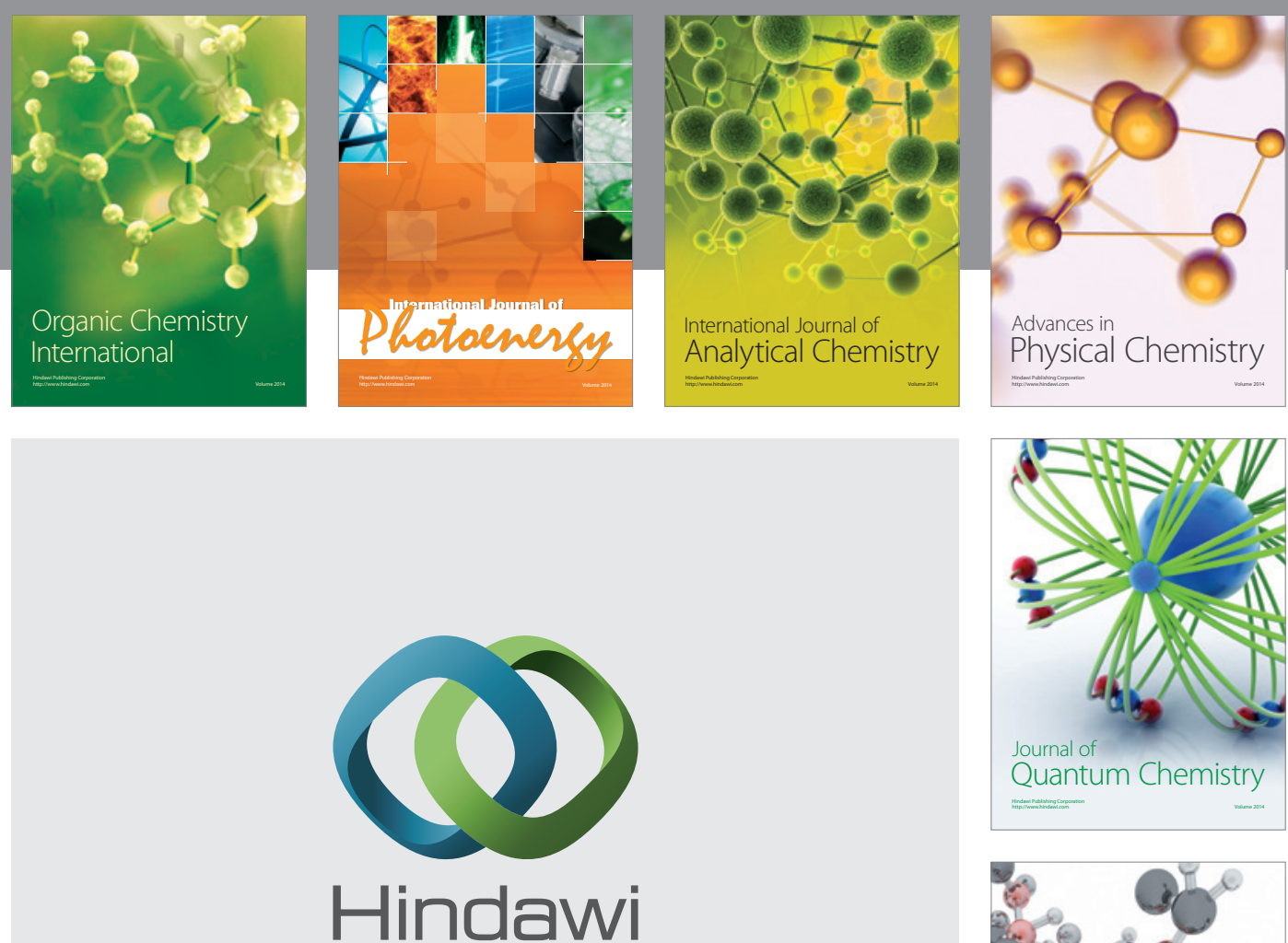

Submit your manuscripts at

http://www.hindawi.com

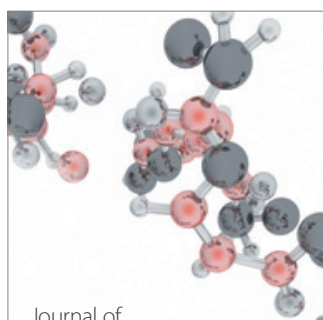

Analytical Methods

in Chemistry

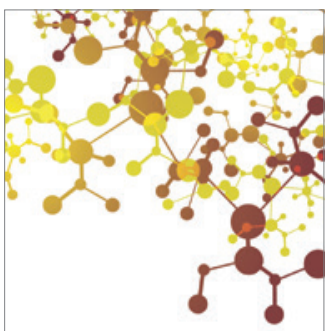

Journal of

Applied Chemistry

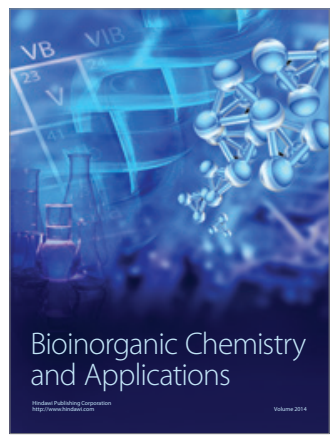

Inorganic Chemistry
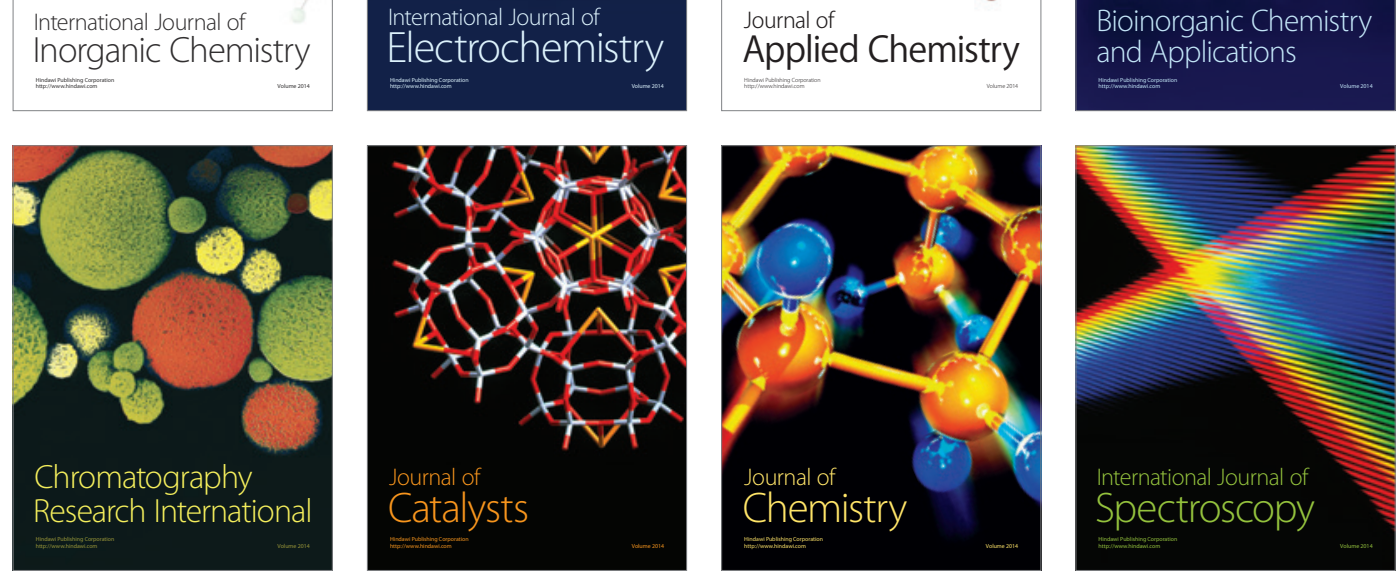